\title{
TODAS AS ÁREAS SE DIZEM PELA LINGUAGEM: PRÁTICAS PEDAGÓGICAS NECESSÁRIAS*
}

\author{
Agostinho Potenciano de Souza, \\ da Universidade Federal de Goiás
}

\begin{abstract}
RESUMO: Lançar um olhar sobre a linguagem não é tarefa apenas do professor de português, mas de todas as áreas de conhecimento, pois um conceito de linguagem como atividade constitutiva dos sujeitos, dos temas, das ciências, da interação, a favor do desenvolvimento da aprendizagem, redimensiona toda ação pedagógica, de modo a transformar o ensino em um processo de letramento eficaz. Essa reflexão teórica, sob o ponto de vista das teorias da linguagem, visa a um aprimoramento das atividades de falar e ouvir, ler e escrever, em todas as disciplinas, de acordo com as realizações de linguagem específicas de cada área, como um desafio para as mudanças educacionais mais urgentes.

Palavras-chave: Linguagem. Ensino. Ler. Escrever.
\end{abstract}

\section{A PALAVRA E O ENSINO}

Raramente, um professor se coloca no lugar do seu aluno. Por que faria isso?

De fato, já sabemos que lugar é esse, pois fomos alunos por um bom tempo. Às vezes, recentemente, sentamos em carteiras como alunos em um curso de pós-graduação. E gostamos da experiência de mudar de lugar. Por quê? Talvez porque o nosso professor-pesquisador tem muitas respostas para perguntas que estamos fazendo ou tem uma variedade de informações mais novas e avançadas em relação ao nosso campo de estudo.

No ensino básico e na graduação, nem sempre o aluno está em busca de informações que nós, professores, auxiliados pelo material didático, trazemos para ele. Talvez, então, o caminho mais curto para chegar até ele,

\footnotetext{
* Artigo recebido em 10/09/2011 e aprovado em 25/11/2011.
} 
tirá-lo da inércia, seja um caminho mais longo e sinuoso, e não o atalho: presta atenção!

Estudar uma área de conhecimento na graduação e na pós-graduação é uma escolha, uma procura; ao passo que estudar as disciplinas do Ensino Fundamental e do Ensino Médio não é uma escolha. Como fica a escuta desse aluno? Ele está à procura de que alguém Ihe diga alguma coisa? Com frequência ele não se faz interlocutor do professor.

Considerando que a atividade de que estamos falando tem na palavra o seu recurso principal de interação, seria de bom auxílio entender o que nos diz Bakhtin:

Na realidade, toda palavra comporta duas faces. Ela é determinada tanto pelo fato que precede de alguém, como pelo fato de que se dirige para alguém. Ela constitui justamente o produto da interação do locutor e do ouvinte. Toda palavra serve de expressão a um em relação ao outro. Através da palavra defino-me em relação ao outro, isto é, em relação à coletividade. A palavra é uma espécie de ponte lançada entre mim e os outros. Se ela se apoia sobre mim numa extremidade, na outra apoia- se sobre o meu interlocutor. A palavra é o território comum do locutor e do interlocutor. (BAKHTIN, 1981, p. 113)

Talvez essas duas faces pareçam muito óbvias, pois nos instalamos à frente de uma turma de alunos e começamos a dirigir-lhes a palavra, imaginando que estão nos ouvindo, que estamos interagindo com eles. Em diversas situações, porém, constatamos que não foram ouvintes, não aconteceu o produto sonhado pela interação: a palavra deles não é a expressão que nós gostaríamos de ouvir, como produto da aula. Falta a condição básica da palavra, os alunos não se tornaram o outro lado da ponte. Em que eles se apoiariam para ouvir o professor?

Temos muitos diagnósticos, conforme a Psicologia, a Sociologia, a Pedagogia e outras ciências, com suas recomendações de solução. E o que teria a ciência da linguagem para auxiliar no encaminhamento de respostas a essa questão fundamental de conhecimento em que todo professor se joga continuamente: como ensinar algo específico, na expectativa de que os alunos aprendam o que ensinamos? Como tornar a palavra"território comum do locutor e do interlocutor"?

Procurando resposta para essa indagação na teoria bakhtiniana da linguagem, teremos que enfatizar uma característica da palavra: a palavra é dialógica. A palavra de um lado da ponte precisa encontrar outra palavra do outro lado que dê resposta, ativando o reconhecimento de reciprocidade. Sem a atitude responsiva, o feedback, a ponte se quebra. 
DA PALAVRA DO OUTRO À PALAVRA PESSOAL

A palavra, matéria-prima da interação, é uma forma de apropriação, num trabalho artesanal, da palavra do outro, a que antes estava em outro lugar. Desde a palavra adâmica, ainda segundo Bakhtin, os discursos se ligam uns aos outros:

As influências extratextuais têm uma importância especial nas primeiras fases da evolução do homem. Essas influências se envolvem na palavra (ou outros signos), e tal palavra é a dos outros, e, acima de tudo, a da mãe. Depois disso, a "palavra do outro" se transforma, dialogicamente, para tornar-se "palavra pessoal-alheia" com a ajuda de outras "palavras do outro", e depois, palavra pessoal (com, poder-se-ia dizer, a perda das aspas). A palavra já tem, então, um caráter criativo. (BAKHTIN, 1992, p. 405)

Tornar própria a palavra é uma engenhosa forma de identificar-se, fazer-se. Tanto como evolução intelectual da espécie humana, desde o início (Adão), quanto na formação pessoal inicial (a mãe), o percurso humano busca na palavra o fundamento de sua construção. No falar, ouvir, ler e escrever a palavra, nos dizemos - me faço eu mesmo. Sem as palavras e os outros signos, não participo ativamente do que é a vida humana, não me incluo no diálogo que toda palavra estabelece. No múltiplo universo das palavras, algumas nos pertencem. Fazemos escolhas, vivemos muitos dos nossos dias com as palavras, acumulamos uma enciclopédia pessoal com elas. Por trás dessa exteriorização, fabricamos os sujeitos que somos - as palavras me compõem, fazem parte de mim.

Talvez não percebamos, mas o nosso conhecimento também faz parte de nossa identidade. As palavras manifestam o nosso grau de desenvolvimento nas diversas competências que temos. Esse modo de ver a linguagem, a palavra e outros signos, como uma transformação da palavra do outro em palavra pessoal, passando por um estágio em que a palavra é pessoal-alheia, pode ser entendido como um ponto de vista sobre o processo de aquisição do conhecimento, da aprendizagem. Essa teoria da linguagem ecoa no que Vygotsky (1978, p. 112) define como Zona de Desenvolvimento Proximal:

É a distância entre o nível de desenvolvimento real, que se costuma determinar através da solução independente de problemas, e o nível de desenvolvimento potencial, determinado através da solução de problemas sob orientação de um adulto ou em cooperação com companheiros mais capazes. 
Essas formulações teóricas sobre linguagem e desenvolvimento nos auxiliam a ressignificar nossas práticas, tanto de linguagem, quanto de aprendizagem. A orientação do professor ("palavra do outro") e a cooperação dos colegas ("palavra do outro") dão as condições para que o aprendiz dê conta da solução de problemas, de forma autônoma, como conhecimento próprio, como palavra pessoal. Este poderia ser o grande projeto dos educadores: agir na Zona de Desenvolvimento Proximal, com práticas dessa migração das "palavras alheias" ao território das palavras pessoais, para que haja um desenvolvimento real dos nossos alunos.

Dizendo de outro modo, a linguagem é, por natureza, constitutiva. Ao percorrer o que os investigadores propuseram como teorias sobre a natureza da linguagem, Carlos Franchi elegeu o conceito de Humboldt, pela formulação abrangente sobre o que faz a linguagem:

A função primordial da linguagem em Humboldt é, pois, no sentido justo que traçamos, não propriamente a de transmitir aos outros nossas experiências, mas a de 'constituí-las'. A expressão que corre por toda a obra de Humboldt é "Bildung": por meio da linguagem o homem "'dá forma' (bildet) ao mesmo tempo a si mesmo e ao mundo, ou melhor, torna-se consciente de si mesmo, projetando um mundo no exterior". (FRANCHI, 1977, p. 19)

A linguagem é uma atividade, por ela o sujeito se constitui, bem como dá forma a suas experiências, ao que sabe do mundo e de si mesmo. A linguagem possibilita tanto o significar lógico, quanto o pensar analógico, que dá suporte ao devaneio, à metáfora, aos universos imaginários. Ela é constitutiva de si mesma, dos sujeitos que a utilizam, dos objetos de cultura dos quais ela fala, das interações entre os sujeitos. Daí, damos à linguagem um caráter de utilidade, pois, com ela, elaboramos nossos pensamentos, explicamos o que vemos, expressamos os sentimentos, damos asas à imaginação. Pela linguagem, organizamos nossas informações, não de modo unilateral, mas conforme cada contexto. Por ela, interpretamos, reavaliamos e, quanto a nós mesmos, nos organizamos; quanto aos outros, conversamos, discutimos, concordamos, discordamos, perguntamos, explicamos, persuadimos. Afinal, comunicamo-nos uns com os outros.

A base do domínio da linguagem de todos é o cotidiano. Ali nascem as palavras, as informações e a interação com os outros, com o mundo, consigo mesmo. A escola tem seus espaços e tempos do cotidiano, entretanto, não é por conta do cotidiano que o professor entra na sala de aula. O professor é outro lugar, é a ciência.

Cada ciência construiu sua língua. Aos poucos as palavras, as declarações de verdade formaram um campo de conhecimento. Para chegar 
ao interlocutor, este deve deixar de ser leigo, tornar-se iniciado no campo, produzir declarações que aquela ciência aprova. Caso contrário, o ouvinte não entra em dialogia, não faz ponte com o falante da ciência. Esta surgiu como uma forma de conhecimento oposta ao mito: os mitos, construções do imaginário, seriam explicações do mundo primitivas, ingênuas; o conhecimento seria um grau elevado, sinônimo de ciência, ou seja, hipóteses submetidas a provas e demonstrações tão lógicas e convincentes que se dão a forma de porta-voz da verdade que estaria contida nas coisas. A ciência se constitui como um campo de veracidade institucional, com estratégias que legitimam seus argumentos.

Esse modo de enxergar a ciência torna-se forte nos últimos dois séculos. É uma concepção produtiva, pois as investigações têm trazido resultados significativos para o que chamamos de desenvolvimento. Em 1905, Einstein produziu uma tese de doutorado e cinco artigos que mudariam a face da ciência - a nova física que proporciona produtos tecnológicos só possíveis no século XX e não nos anteriores: carro, telefone, avião, computador, satélite de comunicação, internet, essa tecnologia que está presente na vida cotidiana é legado de contribuições teóricas.

No entanto, a ciência não possui apenas preocupações práticas, que, quando resolvidas, tornam-se tecnologias; há também a preocupação teórica, como as perguntas que Élcio Abdalla (2005) propõe: o que é aquilo ali, como se dá a formação do mundo, quem fez as leis da natureza? Ou seja, temos perguntas em busca de conhecimentos que não estão ao alcance da ciência disponível hoje, e, talvez, para certas questões nunca haverá ciência: Deus, eternidade, o depois da morte, a origem de tudo.

A ciência, malgrado tenha sido colocada em alta esfera, a dos cientistas, tem alguma proximidade com o cotidiano. Dele retira palavras e frases, porém, com frequência, a ciência tem um código particular. Para entender um código, os parceiros devem entrar em entendimento mútuo. Então, se arbitramos o que é carbono, nos entendemos quando usamos a palavra carbono - e assim por diante, raiz quadrada, crase, gravidade, DNA, barroco, nova história, paisagem.

Sem o código não há entendimento, primeira instância para que os sentidos resultem em uma interação efetiva do sujeito com a significação (ORLANDI, 1988, p. 114). Com o código pode-se declarar, descrever o objeto, o fato - o trabalho inicial dos estudos, a descrição. $O$ código é o primeiro fundamento para o processo interacional entrar no mesmo campo de significação. É o conhecimento prévio do parceiro que torna possível a ele 
transformar ruídos em informação, ou seja, é assim que o partilhamento comunicacional se efetua.

A segunda instância, a interpretação, surge como um crescimento da linguagem em relação ao objeto. Ao relacionar palavras e declarações, com articulações coerentes, com organizações coesas, essa atividade da linguagem clareia a inteligência, vai além da descrição do objeto, pois explicita, revela, persuade. É por esse procedimento de natureza analítica que o sujeito junta informações, sai do campo da simples repetição para a elaboração própria e transforma notícia em conhecimento.

A linguagem como atividade interativa proporciona uma terceira instância, segundo Orlandi (1988, p. 115), a compreensão. Essa leitura mais significativa se dá quando um conhecimento é situado social e historicamente, comparado e colocado em tensão com outros conhecimentos (os mais próximos e outros nem tanto), relacionado com os efeitos que ele exerce no mundo cotidiano, nas pessoas, no planeta: que valores foram agregados em razão desse conhecimento? Há prejuízos? Além da habilidade analítica, o sujeito se encaminha para a crítica e se projeta na metacompetência, porque põe em discussão o conhecimento em relação aos seus usos e valores.

A leitura, atividade de construção de sentidos, por meio de diálogos, provocados ora ao ler, ora ao ouvir, requer essas habilidades de informação (entendimento), conhecimento (interpretação) e sabedoria (compreensão). Essas instâncias não agem compartimentadas, pois se entrelaçam, provocam quebra de linearidade, exigem apoio uma da outra. Embora insistam em pertencer ao mesmo continuum do exercício da leitura, no trabalho pedagógico, podem ser tratadas separadamente, para que cada domínio seja bem desenvolvido. Sem as três instâncias, gradativas e interpenetradas umas nas outras, o sujeito da linguagem não chegará a tirar as aspas de cada palavra que aprende, deixando escapar a oportunidade de constituir a palavra pessoal.

\section{As ATIVIDADES DA LINGUAGEM NA ESCOLA}

Nossas práticas de linguagem podem ser agrupadas em quatro atividades: ouvir e falar (oralidade), ler e escrever (escrita). Se o tempo está ocupado na escola mais ou menos assim: $70 \%$ para ouvir, $20 \%$ para escrever (mais copiar, anotar...), 5\% para falar e $5 \%$ para ler; não seria o caso de buscar um equilíbrio de $25 \%$ para cada atividade, porque todas são fundamentais para o exercício da linguagem? Qual aprendizado resultaria dessa mudança?

O tema é novo para nós como proposta de trabalho pedagógico, de integração do currículo por meio das práticas diversas de linguagem. Não 
é, porém, novidade, para muitos, desde nossas experiências de estudantes. Vários de nós tivemos a sorte de frequentar escolas que davam condições para a prática das quatro atividades. O benefício dessa prática, no entanto, ainda não está universalizado. Convém nos determos em uma reflexão sobre o tema, com o desafio de relacioná-lo a necessidades reais e a soluções que podemos alcançar. É um novo olhar (para alguns, certamente, uma ressignificação de um olhar já constante). Por meio dele poderemos entender melhor, aprofundar conceitos, discutir práticas, pensar em inovações, ocupar-nos em transformar o trabalho docente em algo mais qualificado.

Ouvir e ler são atividades de apropriação das informações e dos sentidos. $\mathrm{O}$ texto, em nome da ciência, é hegemônico, obriga a ser quase decorado pelo aluno. Não haveria outros modos de dizer o que foi lido, diferentes da repetição literal? A apropriação poderia ser dinamizada, caso ouvir não fosse tão dominante e ler tão escasso, em nossas salas de aula!

Se ouvir e ler são atividades de captação e apropriação, as atividades de falar e escrever são de outro âmbito: falo perguntando, dizendo o que não sei (quando isso me é permitido), porém falo também do que sei. Aprendi e falo o que aprendi, de vários modos, da repetição (como papagaio) à elaboração própria e, quem sabe, à criação, à ousadia. A ciência permite ousadia na escola? Quando? Onde? Em alguns casos, surgem os atrevimentos do dizer, nas feiras de ciência, nos jornaizinhos. Na prova, porém, nunca!

Falar e escrever são atividades diferentes, todavia há muitas aproximações: escolhemos as palavras, o modo de construir as frases - na fala quase espontaneamente, na escrita, com mais vigilância. A escrita gasta mais tempo: a caneta e o papel, o teclado e a tela, a escolha mais lenta das palavras, das ideias... Mas a palavra fica registrada, grafada, para reter mais a memória - essa que garante, quando dizemos: - eu sei isso. Escrever permanece um pouco mais externamente e, por experiência de muitos estudantes e suas anotações, dá mais apoio para as demonstrações de ciência que nos são exigidas.

Pelo que observamos em geral, ouvir e ler, posição de interlocutor, poderiam parecer pouco exigentes, em oposição a falar e escrever, posição de locutor. Pensando, porém, a linguagem como atividade interativa, constitutiva, todas as quatro práticas são muito ativas, pois os sujeitos não ficam apenas ouvindo e lendo, como se isso fosse algo passivo. Para alguém tornar-se sujeito da linguagem, participar da dialogia, é necessário que ele trabalhe os sentidos que estão produzidos na interação, nas diferentes atividades do sujeito com a palavra. 
Ao falar, por exemplo, o professor elabora enunciados, algumas vezes, por conta da proximidade em relação ao assunto, de modo quase automático; outras vezes, por falta de familiaridade com o assunto, a formulação torna-se lenta, quebrada, pouco fluida. É que a enunciação é uma produção de sentidos, num jogo de muitas interferências: a escolha das palavras e da construção, a modelação do ouvinte, os objetivos pretendidos. É uma atividade tão complexa que é frequente os outros entenderem diferente o que nós queremos falar - isso resulta da tensão natural que movimenta a relação entre a "palavra do outro" e a palavra pessoal, além da tensão interna à própria linguagem, nos momentos de interação, por interferência do jogo de imagens que produz diferentes efeitos de sentido na comunicação (PÊCHEUX, 1990, p. 79).

Os professores preparam-se para a fala, e essa atividade torna-os cada vez mais entendidos na área específica de conhecimento. Em anos de exercício dessa prática, tornam-se ágeis, formam uma imagem de si perante os interlocutores, provavelmente, confiável, de autoridade - embora não possamos generalizar. Os alunos, por sua vez, quando solicitados a falar, encontram muitas dificuldades, seja pela própria cena de falar em público (mesmo estando com o público dos colegas há vários anos!), seja pela pouca familiaridade com o assunto a ser exposto. Comparando os dois sujeitos da linguagem, na condição de sala de aula, poderíamos inferir que o aluno deveria ser levado a falar mais, pois foi falando para os alunos que o professor adquiriu firmeza no conhecimento que ele expõe.

Com certeza, surgem mil questionamentos a esse tipo de mudança, especialmente porque temos uma longa lista de conteúdos, muitos alunos em cada classe, pouca experiência em fazer da fala um modo de excelência em aprender, para todos. Essa entrada, pela linguagem como interação, na maneira de dar aula que temos vivenciado, terá mesmo de gerar muitas mudanças, pois seu alvo atinge a competência dos alunos em dizer os conteúdos que estão adquirindo, em matemática, história, química e todas as disciplinas. Esse conhecimento, no entanto, tem-se mostrado com resultados não satisfatórios. Não foi de outro modo que isso se manifestou: falta de aptidão em dizer, em expressar produtos de saber, pela linguagem.

Há muitas competências em causa no momento da fala: as palavras certas, o domínio das informações, a entoação (dicção, ritmo, timbre, altura da voz), a adequação ao espaço físico e ao público, a busca da eficácia da comunicação, os gestos que acompanham a fala em colaboração com os sentidos e o envolvimento da atenção dos ouvintes. Tudo isso leva a fala além da própria atividade, pois todos admiramos a arte dos que falam bem, 
ou seja, em nossa área, ensinam muito bem, pois os que ouvem aprendem. Os doze anos de escola básica ainda não nos deram as condições para essa competência da fala. Temos as pessoas, os assuntos, o público - é preciso começar.

Ouvir é uma atividade em espelho com o falar. De um lado a formulação, do outro a compreensão (ORLANDI, 1988, p. 104). São poucos aqueles que têm a habilidade de aprender ouvindo, prestando atenção e retendo os conteúdos, na mesma velocidade em que chegam. Não é fácil manter o foco na fala do professor e apreender as palavras e os sentidos. Por força de envolvimento com a aprendizagem, temos a tradição das anotações em sala de aula: um esforço de apropriação da palavra-alheia, uma procura da palavra-própria. Como estratégia para superar as dificuldades da dispersão, causada pelo não acompanhamento da lógica das informações que estão chegando pelos ouvidos, pela pouca familiaridade com o campo de saber que é o assunto da fala, pela ansiedade vinda da necessidade de compreensão imediata, vários alunos buscam nas anotações uma tábua de salvação. Muitas vezes elas nem são retomadas depois, serviram ali na hora, para dobrar o modo de escuta: ouvindo e escrevendo. Às vezes algum fruto é colhido, pois alguma palavra anotada torna-se palavra própria em outros contextos interacionais.

Ouvir aproxima-se do ler, pois entramos em um processo de captação, um trabalho de decodificação e interpretação. O interlocutor, em atitude responsiva, também elabora sentidos, nessa dialética entre a "palavra alheia" e a palavra própria. Como sujeito ativo da interação, o aluno que aprende a ouvir está em atitude de aprendizagem, não está passivo, pois aciona seu desenvolvimento, sua apropriação da palavra, do saber.

Ler, na escola, além de ser uma prática escassa, é com frequência uma ação orientada para a repetição. Há muitos jeitos de repetir, um deles consiste em responder questionários que mandam apenas reconhecer uma informação, identificá-la, dizer qual é; outro, é lembrar, na hora da prova, o que o livro diz, de forma quase literal, para ter a resposta avaliada como certa. Tanto em um quanto em outro caso, a leitura precedeu a uma escrita que serve mais à cópia que ao entendimento.

Por uma herança negativa, esse procedimento é, com demasiada frequência, considerado o modo adequado de aprendizagem. É preciso refletir sobre essa prática, verificar que objetivos são atingidos, que grau de não desenvolvimento(!) decorre disso para o estudante. Pior, que concepção de educação e formação se configura nesse modo de ler: estudar é memorizar, reconhecer e reproduzir informação? Esse modo de conduzir o ensino, ao 
invés de favorecer a aprendizagem, emburrece e chateia. Monotonia e tédio são os frutos dessa prática. Como seria enxergar o avesso disso?

Ler para aprender. Aprender a ler para apreender o que a leitura permite. Se a cópia é o ponto de partida, que ela seja feita por citações, um recurso de dar relevo a algumas informações, destacá-las (implicitamente há uma solicitação de leitura seletiva, direcionada a determinados objetivos), acompanhadas de comentários; por anotações (tanto de leituras como de escutas); por resumos, dizer o texto com as próprias/alheias palavras, uma textualização com nova organização enunciativa das informações e conceitos em processo de apropriação; por esquemas, de modo geral, o resultado da divisão do texto em partes e a formulação da ideia-central de cada parte; por gráficos, uma forma de esquema realizada com setas, chaves, retângulos e as ligações entre os elementos de referência básica do texto lido. Tais práticas são usuais entre nós, pois aprendemos a estudar assim, a preparar aulas assim. Não seria isso o que falta para nossos alunos gostarem de estudar, aprenderem a aprender?

Essa, porém, é a parte mais primária da leitura, porque há forte ligação com a reprodução, embora os processos sejam não mais, apenas, reconhecer a "palavra do outro", mas, de algum modo, a formulação da "palavra pessoalalheia" - com certeza, um passo bem à frente daquele outro que não sai do lugar, só faz cópia. A leitura, como atividade básica para o aprender e o escrever, deverá desembocar na escrita mais autônoma.

Para que essa sequência progressiva resulte em uma ação pedagógica produtiva, podem contribuir muito os trabalhos em duplas, em grupos momento em que os colegas negociam o aprendizado de produzir sentidos, ancorados nos textos e nos contextos.

Os modos de ler são vários e cada um contribui em um aspecto: a leitura silenciosa e solitária (ora espontânea e sem compromisso, para gostar de ler, ora para buscar informações para uma conversa a seguir - um jeito de estudar); a leitura em voz alta para si e para os outros (ora programada, treinada, tornada solene, valorizando a entoação e o ritmo; ora colaborativa, quando se distribui pela classe, ordenadamente, com comentários pontuados pelo professor e pelos alunos). Não se trata de inventar mil modos (embora a variação ajude a quebrar a monotonia), mas de exercitar a leitura como interpretação, a produção de sentidos que indiquem a compreensão do texto (aspectos linguísticos, textuais e discursivos).

Escrever e ler são práticas de linguagem ligadas uma à outra, por conta da modalidade, a escrita, do mesmo modo que a oralidade faz do falar e do ouvir atividades correlacionadas. $O$ escrever traz referências a textos lidos e, ao 
mesmo tempo, institui a expectativa de que haverá leitura do que está sendo escrito. Desse princípio, inferimos duas características dessas atividades: ao escrever, são deixados traços do que foi lido pelo escrevente, presença de um campo de conhecimento partilhado com outros textos sobre o tema; ao ler o que está escrito, ocorre um diálogo do leitor com os outros textos que ele já leu sobre esse tema. Vemos, então, que são atividades em rede, em relação de reciprocidade.

A cultura escrita é um dos fundamentos da existência da educação, pois vai-se à escola para aprender a ler, escrever e contar. $\mathrm{O}$ escrever se liga ao ler - daí que os produtos da escrita vinculados a textos sejam os mais frequentes na situação escolar: diários de leitura, anotações, resumos, esquemas, resenhas, comentários. Há, no entanto, um alvo mais audacioso: escrever pequenos ensaios (tentativas de dizer de maneira despretensiosa sobre um campo de conhecimento), relatórios de observação ou de leitura (textos narrativos e descritivos, ora objetivos, ora subjetivos), artigos de opinião (textos em que o autor se posiciona frente ao tema com argumentos persuasivos), narrativas (ora relatos do cotidiano, ora histórias recontadas), ficção (narrativas inventadas, às vezes em condição predeterminada por conhecimentos de área; mentiras, ficção científica), entrevistas, artigos de divulgação científica.

Em todas essas formas, o ler e o escrever estão envolvidos numa atitude de pesquisa - o professor indaga sobre os procedimentos de condução de aprendizado, encontra formas diversas de trazer práticas de linguagem (ler, escrever, expor) para que o aluno desenvolva o seu potencial e atinja as competências e autonomias que se esperam dele; o estudante, por sua vez, está fazendo perguntas, tem o desejo do conhecimento, instrumentaliza-se para procurar respostas e expressa-as por escrito.

Entre as questões que cercam a atividade da escrita está a indagação: escrever para quem? Por certo, anotações e esquemas são para uso próprio. Para os demais produtos da escrita, é preciso que sejam buscados interlocutores para eles: os colegas, alunos de outras turmas, os familiares, vez por outra, o professor (temos tantas tarefas, dentre as quais ler, escrever, pensar, planejar, que se torna necessário organizar o tempo de leitura da produção dos alunos, de modo produtivo). Buscar leitores diferentes para os textos dos alunos ainda é, para nós, um aprendizado; porém, de modo algum, deixaremos de programar leitura e produção de texto para o desenvolvimento básico de suas capacidades intelectuais. Mural, cordel, folhas circulando, corredores, jornal - há muitos recursos para incrementar a produção de textos e a busca de leitores desses produtos escolares. 


\section{A INSERÇÃO NO LETRAMENTO}

Essas considerações podem nos levar a descobrir uma confluência para a ação pedagógica. A escola é um espaço coletivo com alta densidade de presença das diferentes linguagens que direcionam a formação fundamental dos educandos. Os professores de cada área, trocando ideias entre si, dialogando com as outras áreas sobre como cada uma desenvolve o ler e o escrever, quais estratégias desenvolve, promoverão a interação e o dinamismo necessários para um conhecimento mais aprofundado das características dessas práticas em sua área de atuação.

São essas ações que incluirão a vida escolar no desafio para o qual somos convocados nas duas últimas décadas: incrementar as condições de letramento de nossos alunos, como bem resume Leite:

[...] um dos grandes objetivos da escola deve ser ampliar ao máximo os níveis de letramento dos alunos, ou seja, possibilitar a eles o envolvimento com as práticas de leitura e escrita durante toda a vida escolar, visando à sua ampla inserção social como cidadãos. (LEITE, 2006)

Essa apropriação das "letras", como leitores e produtores de textos, leva os educandos ao contato com os usos sociais da cultura cultivada, possibilitando-lhes o envolvimento com as práticas sociais (ouvir e falar, ler e escrever) que os auxiliarão a interpretar, a estabelecer significados, a conhecer recursos e estratégias de linguagem, de modo a qualificarem-se para a comunicação e o trabalho.

Com frequência, no entanto, o letramento é feito de modo restritivo, como aprender a regra de três ou a morfologia do aparelho digestivo para se sair bem na prova. E, depois, esquecer. Soares tece a hipótese de que o letramento escolar corre o risco de voltar-se demasiado a padrões internos à escola de tal forma que

[...] as pessoas podem se tornar capazes de realizar tarefas escolares de letramento, mas podem permanecer incapazes de lidar com usos cotidianos de leitura e de escrita em contextos não escolares - em casa, no trabalho e no contexto social. De fato, o termo "letramento funcional" foi criado justamente para ampliar o conceito de letramento definido pela escola, acrescentando a ele comportamentos letrados cotidianos que a aprendizagem formal em contextos escolares não parece promover. (SOARES, 1998, p. 101)

Se a aprendizagem escolar apresenta uma dissonância com a vida não escolar, o aluno pode tornar-se um "analfabeto funcional", ou seja, foi alfabetizado, porém não está preparado para se envolver com as práticas 
sociais de leitura e escrita. Daí que o conceito e a palavra letramento surgem como uma provocação para uma perspectiva mais ampla, crítica e atuante da condição escolar: "Letramento - o estado ou condição que adquire um grupo social ou um indivíduo como consequência de ter-se apropriado da escrita e de suas práticas sociais" (SOARES, 1998, p. 31).

Acentue-se aqui a ligação entre essa definição e a visão de Bakhtin: a palavra/a escrita do outro deve tornar-se a palavra/a escrita pessoal - o sujeito assume a escrita como propriedade, da qual se utiliza em suas diferentes práticas sociais.

Essa maneira de ver a linguagem leva boa contribuição para a resposta da questão posta no início desse artigo: o aluno é um sujeito da linguagem, e ali está como presença responsiva, imagem e interlocutor modelados pelo discurso do professor, do livro didático, da escola. Quando ele aprende a ouvir e falar, ler e escrever, abre um espaço para o professor chegar com os dados da ciência que são esperados e acolhidos.

Confinadas à área de língua portuguesa, as atividades de linguagem têm-se descortinado para um novo olhar, envolvendo pesquisas acadêmicas, práticas de integração entre universidade e escola, de modo a construir um conhecimento de linguagem que, como se propuseram Neves e outros professores, há mais de uma década, possibilitasse "desconfinar a discussão sobre leitura e escrita, ampliando o seu âmbito desde a biblioteca e a aula de português para toda a escola" (NEVES, 2004, p. 11). Uma inovação que está à procura de práticas de linguagem, como ler e escrever, a partir do ponto de vista da história, das ciências, da física e das demais áreas. Algumas boas consequências estão a caminho:"um dos méritos desse desconfinamento foi a descoberta da leitura e escrita como confluências multidisciplinares para a reflexão e ação pedagógica" (NEVES, 2004, p. 11).

Cada disciplina tem suas peculiaridades quanto ao modo de exercitar as práticas de linguagem. Por isso, cabe ao grupo de professores de cada uma delas a pesquisa e a descoberta de como ouvir, como falar, como ler e como escrever no contexto da sua disciplina, para que o aluno adquira o domínio do que é necessário saber em cada uma delas. Compreender a linguagem como constitutiva da ciência, da interação entre locutores e ouvintes, do desenvolvimento da aprendizagem, da necessária dialogia, da atitude responsiva, pode ser um modo melhor de direcionar nossa ação pedagógica e conseguir melhores níveis de letramento. 


\section{ALL FIELDS COMMUNICATE THROUGH LANGUAGE: NECESSARY EDUCATIONAL PRACTICES}

ABSTRACT: Looking at language is not just the task of the Portuguese teacher, but of all the fields of knowledge since a concept of language as the constitutive activity of subjects, themes, sciences and interaction, in promoting learning, is the basis for all pedagogical action if teaching is to be transformed into a process of effective literacy. This theoretical reflection, based on language theories, sets out to improve the activities of speaking and listening, reading and writing in all subjects, in accordance with the language achievements specific to each field, as a challenge for the most pressing educational changes.

KEYWORDS: Language. Teaching. Reading. Writing.

\section{REFERÊNCIAS}

ABDALLA, E. Tecnologia e ciência no centenário do annus mirabilis de Einstein. Exacta, v. 3, 2005, São Paulo, UNINOVE, p. 13-25.

BAKHTIN, M. (V. N. Volochínov). Marxismo e filosofia da linguagem. Tradução de Michel Laud e Yara Frateschi Vieira. 2. ed. São Paulo: Hucitec, 1981.

BAKHTIN, M. Estética da criação verbal. São Paulo: Martins Fontes, 1992.

FRANCHI, C. Linguagem - atividade constitutiva. Almanaque. São Paulo: Brasiliense, 1977. n. 5, p. 9-26.

LEITE, S. A. da S. Sobre o"vovô viu a uva”. Folha de São Paulo. Folha Opinião, 17 mar. 2006. MANGUEL, Alberto. Uma história da leitura. Tradução de Pedro Maia Soares. São Paulo: Companhia das Letras, 1997.

NEVES, I. C. B. et al. (Orgs.). Ler e escrever: compromisso de todas a áreas. 6. ed. Porto Alegre: Ed. da UFRGS, 2004.

PÊCHEUX, M. As condições de produção do discurso. In: GADET, F.; HAK, T. (Orgs.). Por uma análise automática do discurso: uma introdução à obra de Michel Pêcheux. Campinas: Ed. da Unicamp, 1990. p. 78-87.

ORLANDI, E. P. Discurso e leitura. São Paulo: Cortez, 1988.

SOARES, M. Letramento: um tema em três gêneros. Belo Horizonte: Autêntica, 1998. VYGOSTSKY, L. S. A formação social da mente. São Paulo: Martins Fontes, 1978. 
Agostinho Potenciano de SouzA possui graduação em Letras, mestrado em Teoria e História Literária pela Unicamp (1983) e doutorado em Estudos Linguísticos pela UFMG (2003). É professor titular na Faculdade de Letras da UFG desde1993. Leciona na graduação e na pós-graduação em Letras e Linguística. Coordena o grupo de estudos Discurso e Ensino (Discens). Atua principalmente nos seguintes temas: análise do discurso, leitura, escrita, formação de professores e formação de leitores.

E-mail: apotenciano@uol.com.br 